\title{
DOENÇAS PSICOSSOMÁTICAS E MANIFESTAÇÕES NO TRABALHO
}

Jaqueline Tubin Fieira ${ }^{\mathrm{i}} @ 0000-0002-7736-5943$

Centro Universitário União de Ensino do Sudoeste do Paraná - Unisep

Sandra Martins Moreira ${ }^{\text {ii }} \odot 0000-0001-9881-6072$

Centro Universitário União de Ensino do Sudoeste do Paraná - Unisep

Cleusa Bordin Zanellaiii $₫ 0000-0001-8179-273 \mathrm{X}$

Centro Universitário União de Ensino do Sudoeste do Paraná - Unisep

RESUMO: Ao ongo dos anos, o número de pesquisas e estudos voltados para as doenças psicossomáticas estão em maior número e, cada vez, mas embasadas pelo aporte cientifico. Estes estudos relacionam-se às emoções, sentimentos e pensamentos que podem estar em desequilíbrio com diversos fatores, como experiências traumáticas, somatizações e episódios de estresse. Autores renomados, como Sigmund Freud (1956 - 1939) e contemporâneos como Mello Filho, identificaram que o corpo pode adoecer em decorrência de problemas emocionais, pois o organismo é constituído por uma parceria entre mente-corpo que interagem com o fatores culturais, sociais e ambientais. Essas doenças são o resultado do desequilíbrio harmônico ou da desregulação dos campos da mente, corpo e meio externo. Esse artigo teve como objetivo, por meio, da pesquisa bibliográfica e descritiva, apresentar a manifestação dos sintomas psicossomáticos, relacionando o estresse com as atividades de trabalho e, por fim, propor formas para se combater esse tipo de enfermidades. Observamos que as doenças psicossomáticas podem estar ligadas ao estresse advindo do ambiente de trabalho, causando sintomas físicos, entre eles náusea, insônia, gripes, alergias enxaquecas, sudorese, entre outros. No entanto, compreendemos que se faz necessária uma mudança cultural e social na forma como se olha para o trabalhador, fatores que implicam em estratégias e alternativas organizacionais que busque evitar e aliviar esses sintomas. Atividades cotidianas realizadas pelas instituições, como alternativas para que o indivíduo entenda o sentido do seu trabalho, fique tranquilo e satisfeito com suas funções, bem como, com os desafios próprios do trabalho, podem auxiliar na minimização dos sintomas psicossomáticos.

PALAVRAS-CHAVE: Doenças psicossomáticas. Estresse ocupacional. Trabalho.

\section{PSYCHOSOMATIC DISEASES AND MANIFESTATIONS AT WORK}

\begin{abstract}
Over the years, the number of researches and studies focused on psychosomatic diseases are greater and, each time, but based on scientific input. These studies are related to emotions, feelings and thoughts that may be out of balance with several factors, such as traumatic experiences, somatizations and episodes of stress. Renowned authors, such as Sigmund Freud (1956 - 1939) and contemporaries like Mello Filho, identified that the body can become ill as a result of emotional problems, since the organism is constituted by a partnership between mind-body that interact with cultural, social and environmental factors. These diseases are the result of harmonic imbalance or deregulation of the fields of the mind, body and external environment. This article aimed, through bibliographic and descriptive research, to present
\end{abstract}

the manifestation of psychosomatic symptoms, relating stress to work activities and proposing ways to combat this type of illness. We observed that psychosomatic illnesses can be linked to stress arising from the work environment, causing physical symptoms, including nausea, insomnia, flu, migraine allergies, sweating, among others. However, we understand that a cultural and social change in the way we look at the worker is necessary, factors that imply strategies and organizational alternatives that seek to avoid and alleviate these symptoms. Daily activities carried out by the institutions, as alternatives for the individual to understand the meaning of their work, to be calm and satisfied with their functions, as well, as with the challenges inherent to work, can help in minimizing psychosomatic symptoms.

KEYWORDS: Psychosomatic diseases. Occupational stress. Job. 


\section{Introdução}

A ideia de existir doenças de origem emocional tem sido cada vez mais aceita, baseada nisso, podemos encontrar diversos estudos a respeito das interações corpo e alma. Este artigo tem como objetivo principal investigar teoricamente acerca das doenças psicossomáticas manifestas no trabalho.

Neste sentido, há inúmeros estudos sobre a relação do corpo e mente, com o intuito de encontrar outros fatores, e não somente os biológicos como causadores de doenças físicas. É possível afirmar que diariamente inúmeras pessoas caem em armadilhas da mente humana, tornando-se assim escravos que vivem em uma sociedade vendida como "livre".

Vislumbramos que o ser humano mistura-se na massa social confundindo sua identidade com o processo civilizatório. Os valores se inverteram, o consumismo controla a emoção, o excesso de trabalho furta a tranquilidade, vitalidade e a saúde dos trabalhadores. Os índices de doenças psíquicas na sociedade de consumo são explosivas, seguidos por transtornos depressivos e quadros clínicos de ansiedade generalizada. Os fatores psicológicos interligamse com o desenvolvimento das doenças do corpo, afinal, entendemos que não há uma dicotomia mente-corpo.

A palavra psicossomática traz uma nova visão acerca das doenças, que passam a ser entendidas como parte de um processo mais amplo e, não somente, os sintomas que se manifestam. Compreendemos que a causa também é psicológica, mesmo quando o sujeito apresenta mudanças clínicas detectáveis por exames de laboratório, isso significa que, o corpo da pessoa está tendo danos físicos - as doenças psicossomáticas.

Por meio de uma análise bibliográfica e descritiva, este artigo propõe debater teoricamente acerca das influencias e consequências do estresse contemporâneo nos trabalhadores, por atravessarmos um momento histórico de intensa e doentia busca desenfreada pelo "sucesso". Esses aspectos provocam nas pessoas um estado de alerta constante e a crença de que sucesso é possível sem desenvolver doenças físicas e/ou emocionais.

Para realização do presente artigo foi inicialmente realizada uma pesquisa bibliográfica, que é uma das etapas da investigação científica, a qual se caracterizou pela leitura, análise e interpretação de artigos e livros de diversos autores que versam sobre o tema em pauta, com a intenção de reunir os conhecimentos em torno da psicossomática. Num primeiro momento, explanamos teoricamente uma breve história e definições das doenças psicossomáticas. Posteriormente, apresentamos o estresse no trabalho como uma das causas das doenças 
psicossomáticas e propomos formas para o seu enfrentamento. Trata-se, portanto, de uma revisão das literaturas já existentes, com o intuito de proporcionar um aprendizado sobre a área da psicossomática, facilitando sua identificação e seleção dos métodos e conteúdos, servindo de base para a elaboração do artigo.

Quanto à abordagem, o estudo é classificado quanto descritivo. Segundo Diehl e Tatim (2004) essa classificação tem por objetivo descrever a complexidade de um problema e a intenção de algumas variáveis. Torna possível a compreensão e classificação das narrativas a fim de contribuir no processo de mudanças e assim possibilitar maior conhecimento.

Por meio da pesquisa descritiva, descrevemos uma realidade, confrontando hipóteses e correlacionando variáveis para se obter respostas, afim de analisá-las com naturalidade, sem interferências ou manipulações de cunho pessoal. E com isso definir uma relação entre as variáveis no objeto de estudo analisado, que são as doenças psicossomáticas manifestas no trabalho. Justificamos este estudo, como uma forma de estabelecer e encontrar maneiras, para que os profissionais atuantes no mercado de trabalho, possam ter conhecimento acerca da manifestação das doenças psicossomáticas.

\section{Breve histórico da psicossomática}

Desde sua existência, sabe-se que o homem pode ser acometido de diversas enfermidades, e estas estão correlacionadas tanto por fenômenos psíquicos quanto somáticos. Nota-se portanto que as concepções holísticas da doença, são formadas por pensamentos unitários e dualistas do homem e da relação mente-corpo. A medicina contemporânea, e particularmente as pesquisas sobre genética e imunologia, vieram destacar a cumplicidade patogênica entre os fatores ditos externos ao indivíduo e o perfil da sua personalidade (BRANCO, 2005).

Após séculos de evolução do conceito, o termo "psicossomático" foi mencionado pela primeira vez em 1818 por um psiquiatra alemão chamado Heinroth, que utilizou-se da expressão ao se referir a insônia e a influência das paixões na tuberculose, epilepsia e cancro. Já no século subsequente algumas descobertas admitidas a Freud permitiram se obter uma melhor compreensão desses fenômenos. Segundo a história o termo ainda foi reintroduzido por Deutsch em 1922 em Viena (LOPES, 2012).

Anteriormente a psicanálise, dizia-se que as enfermidades eram causadas por agentes externos. Mesmo com diversas iniciativas para buscar-se a compreensão da relação corpo e mente. A própria origem do termo psicossomática por Johann Heinroth em 1828 atesta isto. 
Aonde ele presume que paixões sexuais são relevantes para o aparecimento de diversas enfermidades como tuberculose, epilepsia e câncer, evidenciando a importância dos aspectos físicos e psíquicos incorporados ao processo de adoecer (VOLICH, 2000).

A psicossomática é uma evolução das investigações psicanalíticas que colaboram para o campo com dados a respeito da origem involuntária das enfermidades, em especial dos estudos das paralisias e anestesias histéricas que se originam das contribuições pré-psicanalíticas de Jean-Martin Charcot e Josef Breuer (LOPES, 2012).

O termo doença psicossomática foi inicialmente utilizado para tratar de apenas determinadas doenças como a úlcera péptica, colite ulcerativa, hipertensão arterial, e asma brônquica, e onde as relações psicofísicas se mostravam muito claras. Futuramente percebeuse que tal concepção também é eventualmente válida para todas as enfermidades (MELLO FILHO, 2005).

\section{Definições iniciais da psicossomática}

Durante séculos, e mesmo até a teorização pela psicanálise, considerava-se que as doenças eram causadas por agentes externos, com ressalva dos males congênitos e hereditários. O surgimento da Psicanálise e sua gradual aceitação revolucionaram esse conceito e incorporaram um novo: o de que algumas doenças ou males do corpo constituíam uma mera expressão da psique, ou seja, vinham de dentro da pessoa. A medicina Psicossomática, relativamente recente, se estabeleceu a aproximadamente 50 anos (RIBEIRO, 2004).

As doenças psicossomáticas estão relacionadas a emoções, sentimentos e pensamentos que podem estar em desequilíbrio por diversos fatores, como traumas não superados e estresse.

A psicossomática é uma ciência interdisciplinar que integra diversas especialidades da medicina e da psicologia para estudar os efeitos de fatores sociais e psicológicos sobre processos orgânicos do corpo e sobre o bem-estar das pessoas (SEAWARD, 2009, p. 38).

De acordo com Seaward (2009), as lesões psicossomáticas são tipicamente enigmáticas, pois podem surgir de uma hora para outra e do mesmo modo que se manifestam vão embora. Ou ainda, podem se complicar e colocar em risco a vida do indivíduo, como um agravamento do quadro ou até mesmo a morte. 


\section{DOI 10.33872/revcontrad.vlnl.e005 | v. 1, n. 1| Jan./Jun. 2020}

Silva (2016, p. 57) afirma que "é comum ao analisar as pessoas acometidas pelas doenças psicossomáticas, identificar que elas possuem perfis de todos os gêneros, (...) todas elas podem desenvolver esta patologia, desde que sejam expostas aos ambientes propícios."

A mesma autora ressalta que é importante observar que a personalidade de cada indivíduo é formada pelo que chamamos de temperamento (parte genética herdada de parentes) e pelo caráter que é formado por experiências vividas cotidianamente, diante disso ela afirma que algumas pessoas estão mais suscetíveis ao desenvolvimento dessas doenças (SILVA, 2016).

Há aspectos frequentemente encontrados em pessoas que estão mais suscetíveis, por terem comportamento de se cobrar demais, com dificuldade de relaxar, e de solicitar ajuda de outras pessoas. Estas, tendem a ser pessoas pessimistas, com tendências de ter preocupações em excesso, indivíduos que necessitam ter o controle, e com preocupação em satisfazer as necessidades alheias. Portanto, as pessoas com um ou mais aspectos costumam ser pouco flexíveis e muito estressadas. Por isso, tendem a reagir mal perante as adversidades e frustrações, contribuindo assim, para a geração de diversos sintomas, dentre os mais relevantes pode-se citar estresse, dores de cabeça ou de barriga, palpitações, tremores, boca seca, enjoo, náusea, perda de desejo sexual e baixa autoestima. Todos esses sinais misturam emoções. (SILVA, 2016).

\section{Manifestações psicossomáticas}

A definição de sintoma passou por grandes mudanças e teve sua evolução na definição através dos estudos de Freud (1982). No sintoma psicossomático o corpo é atacado, as angústias recaem sobre ele, ou não se derivam adequadamente. Ele não se torna impotente ou inibido, mas entra em uma espécie de sofrimento e pode desarticular-se gravemente. Segundo o autor, o sintoma psicossomático surge como uma investida de interferir no processo (RANGEL; GODOI 2009).

Desta forma, entende-se que é a manifestação de algo que está disfarçado, de algo que muitas vezes é desconhecido, e não conseguindo de outra forma vir à tona, acomete assim o corpo, em enfermidade. Pode-se supor que o corpo expressa, põe pra fora as emoções que as vezes ocultamos de nós mesmos. Nosso corpo fala através de gestos, mímicas, contraturas, calor, tremor, dores de barriga, travamento dos dentes, enfim, com tantas demonstrações físicas (RANGEL; GODOI, 2009). 
Nota-se que nem sempre há conexão com o que expressamos verbalmente, sobre isso podemos mentir, desempenhar papéis, tolerar o intolerável. Mas nosso corpo exprime as emoções mais verdadeiras, porque as emoções são incorruptíveis. Quando há somatização, temse a consciência de que força-se além da conta uma emoção. E assim, desenvolve-se um resfriado, uma herpes, uma enxaqueca. Mas em grande parte das vezes as pessoas são rígidas, e continuam a desempenhar os mesmos papéis, e assim desconectando das próprias nossas emoções, ocorre então a desconexão mente/corpo do sintoma (TÓFOLI; GONÇALVES; FORTES, 2013).

Dentre o número extenso de sintomas existentes no trabalho, destacam-se os mencionados abaixo, que tem relação efetiva com o estresse.

Tabela 1 - Lista de sintomas relacionados ao estresse

\begin{tabular}{|l|l|}
\hline 1-Dor de cabeça de tensão & 12- Alergia \\
\hline 2- Dor de cabeça tipo enxaqueca & 13-Periodos de Tonturas \\
\hline 3- Tensão muscular (pescoço e/ou ombros) & 14- Palpitações cardíacas (coração acelerado) \\
\hline 4- Tensão muscular (coluna dorsal) & 15-Insônia \\
\hline 5-Dor na articulação & 16-Pesadelos \\
\hline 6-Gripe & 17-Fadiga \\
\hline 7-Resfriado & 18-Hemorróidas \\
\hline 8-Dor de estômago & 19-Espinhas \\
\hline 9- Diarreia & 20-Cãibras \\
\hline 10- Úlcera inflamada & 21- Acidentes Frequentes \\
\hline 11- Ataque de asma & 22-Suor excessivo \\
\hline
\end{tabular}

Fonte: Seaward (2009).

Dentre os sintomas apresentados, é fácil verificar o aumento dos batimentos cardíacos quando leva-se um susto, ou quando nos irrita-se com alguma coisa, quando há críticas e há ameaças de forma física ou moralmente. Acompanhado da taquicardia surgem outros sintomas, podendo ser diferente em cada pessoa. As pessoas que sofrem com problemas psicossomáticos não vêm correlação do que sentem fisicamente com algum problema emocional (SEAWARD 2009).

Segundo este autor, ainda é comum sentir dor, e a mesma pode manifestar-se em três níveis:

- Sinal de registro, uma ameaça à integridade estrutural ou funcional do organismo; 


\section{DOI 10.33872/revcontrad.vlnl.e005 | v. 1, n. 1| Jan./Jun. 2020}

- Ela pode ser repartida/comunicada a outra pessoa/pedido de ajuda;

- A dor é utilizada como forma de manipular os outros, ganhar o controle sobre eles, aliviar culpando alguém por uma falta real ou imaginaria.

Esses sintomas, que se manifestam como se fossem físicos e que realmente incomodam, têm seus processos emocionais sujeitos a todo instante em nossa vida, nem todos os indivíduos percebem, mas quando relembram um fato doloroso pelo qual se passou, ou a simples recordação do episódio provoca novamente os mesmos sintomas no organismo, e isso é chamado Realimentação (RODRIGUES, 2019).

A autora acima mencionada explica porque que isso ocorre, pelo fato de que o nosso cérebro "não sabe distinguir" entre o que é real e o que é uma simples lembrança, para ele tudo e real, e o nosso cotidiano é assim, a todo momento temos flash de memórias, mesmo que nem nos damos conta, mas o cérebro age em consequência, e assim se dá uma constante realimentação das emoções e dos sintomas recorrentes (RODRIGUES, 2019).

E assim, no decorrer do tempo, os sintomas se tornam tão frequentes que passam a incomodar, o que nos leva a procurar um médico, o qual após solicitar diversos exames, afirma que se trata de uma doença "emocional" e prescreve calmantes, que podem funcionar, mas que não eliminam definitivamente os sintomas (RODRIGUES, 2019).

Cada vez que se tem um pensamento negativo, ele reagirá com uma emoção negativa (raiva, ansiedade e tristeza) e isso ativará o sistema nervoso, colocando o corpo em estado de alerta. As emoções positivas (alegria, felicidade e amor) reparam e recuperam o organismo, e estimulam o sistema imunológico. Diante disso, estudos demonstram que as pessoas otimistas têm tendência a viver mais tempo e com melhor saúde que aqueles que se deixam invadir pelo pessimismo (RODRIGUES, 2019).

\section{Relação entre as doenças psicossomáticas e o trabalho}

Segundo Carvalho (2016) as doenças psicossomáticas são de difícil identificação, pois muitas vezes não tem uma causa específica para o seu aparecimento, além de que fazem o indivíduo sentir-se desacreditado diante dos outros. A sensação de fraqueza, frustração, infelicidade e incapacidade não deixam que a pessoa realize sua rotina de atividades dentro da organização.

Além disso, quando se pensa em qualidade de vida versus resultados empresariais positivos, faz-se com que o trabalhador e organização possam se destacar no mercado. Se o colaborador possui uma qualidade de vida boa, irá se desenvolver melhor e, como 
consequência, fazer com que a empresa cumpra suas metas e seus objetivos com sucesso. Assim, pode-se dizer então que doenças psicossomáticas são resultado da falta de qualidade de vida no trabalho (CARVALHO, 2016).

O reconhecimento do ser humano, além da preocupação com emoções, sentimentos, e também com qualidade de vida são fatores que fazem diferença. Para o homem, o trabalho é sua forma de interação e transformação com o meio ambiente, desta forma, assegura sua sobrevivência, além de estabelecer relações interpessoais, que teoricamente serviriam para reforçar a sua identidade e o senso de contribuição. Cada indivíduo traz uma diferente história de vida, que são maneiras diferentes de pensar e de levar a vida, e isso reflete em seu trabalho, e em como ele é visto por cada ser humano. Algumas pessoas são mais ouvintes, outras nem tanto, há pessoas que constantemente se interessam em aprender, outras não, enfim cada indivíduo possui objetivos diferenciados e nestas situações seguem priorizando o que acreditam ser melhor para si, mesmo que as vezes isso resulte em conflito com a própria empresa (CUNHA; LIMA; ALVES; 2016).

Bom Sucesso (1997) identificou algumas das dificuldades mais observadas na percepção de como o sujeito atua no trabalho, entre elas, destacam-se: dificuldade em ouvir, falta de objetivos pessoais, e dificuldade em priorizar. Também é sempre bom lembrar que cada ser humano é único, e assim reage unicamente e individualmente a situações semelhantes. $\mathrm{Na}$ hipótese idealizada de pleno emprego, mesmo com ótimas condições financeiras, conforto e segurança, alguns colaboradores ainda se encontrarão tomados pelo sofrimento emocional. Outros, necessitados, buscando o alimento diário com esforço excessivo, ainda assim se declaram felizes, esperançosos.

Por outro lado, além de compor responsabilidade da empresa, qualidade de vida é também uma vitória pessoal. $\mathrm{O}$ autoconhecimento e a evidenciação da função de cada ser humano nas instituições, da postura facilitadora, empreendedora, passiva ou ativa, transformadora ou conformista é responsabilidade de todos. Um ajuste funcional tem como objetivo a garantia de conforto, bem-estar, satisfação e segurança para os funcionários, assegurando aos clientes melhores condições de visualização dos produtos, além de compor um ambiente saudável e agradável de ser visitado. O espaço físico deve oferecer flexibilidade na disposição dos materiais e bom aproveitamento do espaço. Cabe ainda a empresa oportunizar aumento dos níveis de qualidade, produtividade e corte dos desperdícios. Esses elementos em si não têm como objetivo promover a satisfação, mas a sua ausência pode sim inibi-la (CUNHA; LIMA; ALVES; 2016). 
De outra forma, os fatores de motivação, como a oportunidade de auto realização, reconhecimento pela qualidade e dedicação no trabalho, a atratividade do próprio trabalho em si e a possibilidade de desenvolvimento pessoal e profissional do trabalhador são motivadores em essência. Assim, se o trabalho for executado sob condições inadequadas tanto pelo aspecto da composição do ambiente físico quanto pelo estilo das relações de trabalho na organização, podem trazer graves consequências a saúde, tanto de ordem psíquica quanto física, causando assim prejuízos na interação do indivíduo com o próprio trabalho (CUNHA; LIMA; ALVES; 2016).

O estresse no trabalho, com o passar dos tempos e com o avanço da tecnologia (automatização) deixou de caracterizar-se como estresse físico, dando margem ao surgimento do estresse emocional. Esse desgaste emocional que as pessoas são submetidas nas relações com o trabalho é fator muito significativo na determinação de alguns transtornos como a ansiedade patológica, pânico, fobias, doenças psicossomáticas, enfartes, derrames etc. O estresse emocional gerado pelo trabalho vem associado à pressão social e a pressão psíquica de cada indivíduo. Por exemplo, quando trabalhamos, nos sentimos úteis, produtivos e até mesmo realizados, mas o estresse pode ocorrer por diferentes situações, como um simples desentendimento com colegas ou mesmo diante da monotonia ou da sobrecarga, da corrida contra o tempo, da insatisfação salarial, até da permanência ou não no trabalho (JORGE, 2004).

Quando se fala em prevenção e atenção do estresse no trabalho, aparecem desafios, pois os gerentes e empregadores normalmente procuram resolver individualmente o problema dos empregados, recusando-se a interferir em sua real origem. Quando isso acarreta a necessidade de mudanças no local de trabalho, pela provável separação entre o lucro econômico e o bemestar dos colaboradores (JORGE, 2004).

O objetivo primordial deve ser a prevenção primária. As atitudes eficientes têm comprovado efeito econômico nas empresas, ao aprimorar o estado de ânimo e bem-estar dos servidores, reduzindo as enfermidades, diminuindo as ausências, aumentando a produtividade e melhorando consideravelmente o desempenho e a qualidade do trabalho. Algumas das ações particulares conduzem-se para as características de estrutura da organização, estilos de comunicação, processos de formulação de decisões, cultura corporativa, funções de trabalho, ambiente físico e métodos de seleção e capacitação do pessoal (JORGE, 2004).

As ações de mudança da instituição buscam a reformulação dos processos e tarefas e permitem desenvolver as capacidades do servidor, aumentando sua responsabilidade e meios de comunicação por intermédio de programas de auxílio para os trabalhadores, círculos de qualidade, grupos de assessoria, apoio, participação ativa, trabalho de equipe, solidariedade 
laboral, desenvolvimento profissional, promoção de sua criatividade e processos de melhora contínua. Mudanças também podem ser propiciadas por meio de uma inclusão gradativa dos colaboradores à organização por meio de diversas estratégias, como desenvolvimento organizacional, adequação dos estilos de liderança, melhorias no processo comunicacional, redistribuição do poder e autoridade e atuação responsável e ativa nos processos de tomada de decisões das áreas (JORGE, 2004).

Já no aspecto de prevenção pessoal, os projetos de atenção exclusivos nos locais de trabalho abrangem a disseminação de informações sobre o estresse, suas origens e a maneira de controle, por meio da educação para a saúde dos trabalhadores, para que eles desenvolvam habilidades pessoais que lhes permitam diminuir o problema. Por exemplo identificando os agentes causais do estresse e conscientizando o trabalhador, mostrando-lhes as diferentes possibilidades de solucionar a situação, ou o manejo inteligente do estresse para poder atuar em consequência e combatê-lo (JORGE, 2004).

Assim, se faz necessário o uso de diversas estratégias para auxiliar os trabalhadores, como por exemplo a administração do tempo, priorização de problemas, desenvolvimento da capacidade de planejamento, técnicas de negociação, assim como exercitar habilidades para a tomada de decisões, solução de conflitos, conduta assertiva, manejo do tempo, e, em geral, o desenvolvimento de melhores relações humanas. Pois indivíduos que trabalham com o que gostam, em lugares aconchegantes, tendem a ter menos problemas relacionados ao estresse. Isso tudo devido às energias e vibrações que o meio nos proporciona. Quanto mais positivo e agradável o espaço, menor a chance de termos uma reação negativa. Estar em um lugar acolhedor é bom para o estresse (CUNHA; LIMA; ALVES; 2016).

\section{Estresse ocupacional}

Para o autor Seaward (2009), o fenômeno estresse como é conhecido hoje em dia, é muito novo em relação a história da humanidade e passou a ser a ser uma expressão familiar nas últimas três décadas, pois até os anos 1960, esse termo não era encontrado nos textos e manchetes.

O surgimento do estresse ocorreu a partir do momento em que houve a introdução dos produtos de consumo, criados como objetos de luxos para adicionar mais tempo livre a semana de trabalho, como os fornos, micro-ondas, máquinas de lavar, celulares, notebooks e televisores. Entretanto, ao invés de contribuir, trouxe alguns pontos negativos, tanto para os usuários, quanto para os fabricantes e seus colaboradores (SEAWARD, 2009). 
Mas à medida que a produção de itens de alta tecnologia aumentou a atividade competitiva para aumentar o esforço humano e a produtividade, que sucessivamente diminuiu o tempo livre e criou uma série de comportamentos insalubres (SEAWARD, 2009).

Segundo Seaward (2009), o termo Tecnoestresse é usado para definir o resultado de uma vida em ritmo acelerado dependente de vários meios de tecnologia, incluindo computadores, telefones celulares, os quais foram criados com o intuito de que dariam mais tempo de lazer às pessoas. Em vez disso, as mesmas tornaram-se escravas, viciadas no uso constantes destes aparelhos.

Segundo Silva (2016), esse problema parece ter alcançado cada canto do planeta e após conduzir vários estudos sobre o tópico de stress e doenças a Organização Mundial de Saúde chegou a uma conclusão que o estresse é uma epidemia global, e parece não priorizar idade, raça, gênero, religião, ele é chamado "o destruidor de oportunidades iguais", pois quando não resolvido pode abalar todos os aspectos da vida.

$\mathrm{Na}$ Era contemporânea a palavra estresse é usada para descrever o nível de tensão que as pessoas sentem que é colocada sobre suas mentes e espíritos pela demanda de trabalho. Psicologicamente, o estresse, é um estado de ansiedade produzido quando eventos de responsabilidades excedem a capacidade de enfrentamento de alguém (HAANEL, 2009).

Para este autor a palavra estresse tem muitas definições, na perspectiva oriental é considerada a ausência da paz interior, na cultura ocidental pode ser descrito como uma perda de controle.

Seaward (2009) comenta que "o estresse é uma resposta fisiológica e comportamental normal a algo que aconteceu ou está para acontecer que nos faz sentir ameaçados ou que, de alguma forma, perturba o nosso equilíbrio". Ou ainda fisiologicamente falando, é definido como a taxa de desgaste sobre o corpo, onde não se sabe a diferença entre o estresse bom ou ruim, por exemplo, uma promoção no emprego, ou a perda de um emprego.

O estado de saúde ou doença não era uma medida da integridade ao sistema inume, mas da força do micróbio invasor, posteriormente Bernard que apresentou o termo homeostase, admirou-se da complexidade da fisiologia humana. Ele sugeriu que não eram os germes que causavam o estrago, mas as condições do corpo e do estado de saúde que destruíam os germes, ou eram destruídos por eles, usando uma metáfora entre sementes e de psicossomático, que definiu a relação entre mente e corpo. Apesar do cuidado com a saúde, estimativas sugerem que até $80 \%$ de todas as visitas ao médico são resultadas do estresse (SEAWARD, 2009).

Ainda conforme Seaward (2009), especialistas, estimaram 75 a $85 \%$ dos problemas relacionados à saúde são agravados pelo estresse, podendo variar de herpes a hemorroidas, gripe 
comum e até câncer. Todos os trabalhadores são pessoas humanas e suas vidas precisam de uma continuidade quando deixam os portões da fábrica, o elevador da firma ou a porta do colégio, então, como consequência se lançam nas atividades mais desejadas e criativas.

Conforme pesquisa da representação brasileira da Associação Internacional de Manejo do Estresse (ISMA), 72\% dos brasileiros ativos no mercado de trabalho experimentam alguma sequela provocada pelo estresse, estas que podem progredir para outras doenças, como doença coronariana, câncer, resfriados comuns, enxaquecas, verrugas, infertilidade, ulceras, insônias e hipertensão (AMENDOLA; CAMBRICOLI, 2019).

Passamos cerca de 1/3 das horas do dia no trabalho. Isso nos leva a esperar que o trabalho atenda diversas de nossas necessidades físicas, sociais, egoísticas e que, além disso, essas necessidades possam ser satisfeitas de muitas maneiras diferentes fora do trabalho, em torno do trabalho e por meio do trabalho (SEAWARD, 2009).

O autor ainda complementa que, nem sempre foi assim. Ao dar uma olhada para o ontem, identificamos que a muitos anos a maior parte das pessoas vivia numa zona rural, a família construía a unidade econômica básica, e o pai trabalhava no campo e a mãe preparava a alimentação, naquele tempo não havia supermercados e a dona de casa lavava e cozinhava.

De acordo com Gazzotti e Vasques-Menezes (1999), quando faltam suportes afetivos e sociais, gera-se uma fragilidade que provoca grande sofrimento, visto que o reflexo dessa situação não fica limitado à vida privada, estendendo-se para o campo das relações de trabalho. O trabalhador, tem um aumento da tensão emocional ao encontrar-se sem alternativas para compartilhar suas dificuldades, anseios e preocupações, e esta tensão pode acarretar no que chamamos de síndrome de burnout e/ou estresse ocupacional.

As relações de trabalho eram as mesmas. Se o homem não era seu patrão, as relações entre eles eram fáceis, onde o trabalho dava muita satisfação, as pessoas se conheciam participavam das festas, riam juntas, sofriam, mas depois vieram os supermercados, e o homem veio para a cidade e apareceram as indústrias e a cidade cresceu, o homem abandonou o campo e o trabalho começou a ser subdividido, surgiram às especializações, e tudo isso além de vantagens, trouxe também desvantagens, com o aborrecimento e a perda do sentimento de importância pessoal, do orgulho de estar fazendo alguma coisa importante (SEAWARD, 2009).

O progresso industrial fez a empresa crescer e tornou o chefe cada vez mais distante. Antigamente o aprendiz conversava com seu patrão, hoje um homem pode passar a vida inteira numa firma sem sequer ter conversado uma vez com o gerente ou menos com o presidente. Há escolas em que os alunos não chegam a conhecer o diretor e não sabem o nome de todos os seus professores. Esse tipo de abordagem impessoal que o progresso industrial trouxe está longe de 
DOI 10.33872/revcontrad.vlnl.e005 | v. 1, n. l| Jan./Jun. 2020

provocar o entusiasmo do empregado, pois estes acham preferível um patrão mal conhecido a um chefe impessoal nunca visto (SEAWARD, 2009).

Diversos pesquisadores, consideram o estresse ocupacional como algo complexo. Tratase de um termo antigo, porém passou a se tornar relevante e tem se tornado novo campo de estudo com do surgimento de doenças que estão sendo vinculadas ao estresse no trabalho, como por exemplo, hipertensão, úlcera, entre outras. Logo, o conceito de estresse ocupacional se dá como: "decorrência das relações complexas que se processam entre condições de trabalho, condições externas ao trabalho e particularidades individuais de cada trabalhador, nas quais as demandas do trabalho superam a competência do trabalhador para enfrentá-las. Acarretando efeitos sob forma de problemas na saúde física e mental e na satisfação no trabalho, comprometendo o indivíduo e as organizações" (FERNANDES, MEDEIROS, RIBEIRO, 2008).

O estresse ocupacional pode acarretar em diversas doenças como a já citada anteriormente síndrome de burnout, sua definição consiste no entendimento social-psicológico de Maslach \& Jackson, que considera burnout como uma reação à tensão emocional crônica pelo excesso em enfrentar pessoas (FERNANDES, MEDEIROS, RIBEIRO, 2008).

Trata-se de uma síntese de ideias formada por três dimensões associadas, porém independentes:

a) exaustão emocional: determinada pela falta de energia e entusiasmo, trazendo uma sensação de exaustão de recursos que pode se juntar ao sentimento de frustração e tensão nos trabalhadores, por compreenderem a escassez de condições que demandem mais energia para o atendimento ao cliente, por exemplo, diferente de como faziam antes;

b) despersonalização: caracteriza-se pelo progresso de uma insensibilidade emocional, que faz com que o profissional se torne mais desumano diante do tratamento aos clientes, colegas e a organização;

c) diminuição da realização pessoal no trabalho: caracterizada por uma predisposição do trabalhador a autoanalisar-se de forma negativa, o que gera infelicidade e insatisfação com seu desenvolvimento profissional, com decorrente queda em seu sentimento de competência e êxito, bem como de sua capacidade de interação (CARLOTTO, PALAZZO, 2006).

\subsection{Enfrentamento do estresse}

O estresse já atinge $90 \%$ da população do planeta, de acordo com dados divulgados pela Organização Mundial de Saúde (OMS). O mesmo é vital, mas em excesso pode matar, ou seja, 
essa tensão não pode durar por muito tempo, porque em altos níveis esforçam o coração e vasos sanguíneos para a produção de cortisol, e isso provoca um desequilíbrio no sistema imunológico, podendo chegar a reações inflamatórias. Assim, estima-se que de $75 \%$ a $90 \%$ das patologias estão relacionadas ao estresse crônico. Com isso, tem-se buscado cada vez mais formas de amenizar ou até mesmo enfrentar o estresse (SEAWARD 2009).

Diversos estudos nos mostram que algumas atitudes tem gerado resultados positivos para se combater o estresse, como por exemplo:

- Identificação da causa e eliminação das situações de conflito: é importante que se tente buscar uma causa para o aparecimento do estresse, e se possível que se possa eliminar as situações as quais estejam causando esse tipo de sensação (FERRARI, 2012);

- Definir limites e prioridades: É muito importante definir as prioridades para não se sobrecarregar, pode-se por exemplo fazer uma lista das atividades mais urgentes e estabelecer limites para realizá-las, trazendo assim uma sensação de mais controle sobre sua vida (FERRARI, 2012);

- Alimentar-se de maneira saudável e regularmente: Sabemos que a qualidade de nossa alimentação e a forma como nos alimentamos repercute em nosso estado geral de saúde. Dar preferência a alimentos naturais e manter horários para as refeições é uma maneira eficaz de se evitar o estresse (FERRARI, 2012);

- Ter momentos relaxantes: como ouvir música, assistir um bom filme, caminhar em meio a natureza, ou até mesmo praticar meditação: Para Toby Maguire, especialista em administração do estresse no The Body Holiday, St. Lucia, ela permite que o indivíduo se liberte de seus pensamentos e emoções vendo as coisas de uma perspectiva muito mais clara, sendo assim uma das melhores maneiras para acalmar uma mente atribulada (FERRARI, 2012);

- Praticar atividades físicas: Atividades físicas são de extrema importância para que a pessoa tenha um dia-a-dia produtivo, com o estresse que passam conforme as atividades que exercem, é preciso que tenham atividades que sejam resultantes de um alívio desse estresse, assim os exercícios tendem a proporcionar um relaxamento do corpo e da mente (SÉPE 2011);

- Aprender a viver no presente: Deixar de se preocupar inutilmente por coisas que talvez sejam improváveis de acontecer, podem ajudar a não sofrer por antecipação, evitando o estresse (SEAWARD 2009); 


\section{DOI 10.33872/revcontrad.vlnl.e005 | v. 1, n. 1| Jan./Jun. 2020}

- Dormir bem: Uma boa noite de sono é de suma importância para a recuperação de nossa saúde física e mental (FERRARI, 2012).

De acordo com Sépe (2011) o estresse é combatido através de uma melhor qualidade de vida, e para que isso ocorra existem alguns instrumentos geralmente utilizados nas organizações, como "palestras, leituras, filmes, debates e eventos de valorização da saúde organizacional". Porém, apesar de muitas empresas terem uma preocupação referente a isso nos dias atuais sabe-se que uma empresa sozinha não consegue melhorar a qualidade de vida, por mais que sejam realizadas essas atividades, é necessário uma mudança em nível social e cultural.

\section{Considerações finais}

As relações de trabalho não são mais as mesmas, o progresso industrial fez a empresa crescer e tornou o chefe cada vez mais distante. Antigamente o aprendiz conversava com seu patrão, hoje um homem pode passar a vida inteira na mesma empresa sem sequer ter conversado uma vez com o gerente ou presidente.

Atravessamos a era da informação e mudanças tecnológicas, nomeando esse termo como tecnoestresse, que é usado para definir o resultado de uma vida em ritmo acelerado, que dependente de vários meios de tecnologia. Entre eles, estão inclusos os computadores, telefones celulares, os quais foram criados com o intuito de que dariam mais tempo de lazer às pessoas, em vez disso, tornaram-nas escravos, viciados no uso constantes destes aparelhos.

Contudo, sabe-se que muitos indivíduos só conseguem manter seu equilíbrio e obter satisfação graças ao trabalho, porém da mesma forma que o trabalho contribui para o desenvolvimento, também pode significar sofrimento mental, em decorrência das más condições em que é realizado.

As emoções que afetam os indivíduos no ambiente de trabalho, e que podem gerar doenças, são definidas como doenças psicossomáticas, uma vez que o organismo é constituído pela parceria mente-corpo, que interagem com o ambiente como um conjunto, e que a saúde ou doença é o resultado do equilíbrio harmônico dos mesmos.

As doenças psicossomáticas referem-se aos sintomas, doenças, queixas físicas ligadas ao psíquico. Eles são a manifestação de algo que está escondido, e que muitas vezes é desconhecido, e que não consegue outra forma de manifestação, encontrando um local do corpo, em enfermidade. Em função disso, identifica-se um grande número de sintomas, sendo os mais comuns como vômitos, diarreias, alterações no estômago e intestino, alterações no sistema 
respiratório (asma, bronquite), cólicas renais, cólicas menstruais, enxaquecas, hipertensão entre outras.

A pesquisa possibilitou entender teoricamente a manifestação das doenças psicossomáticas, conhecer os diferentes sintomas, e associá-los ao cotidiano, e ainda, apresentou possibilidades de minimizar os impactos na sua saúde do trabalhador. Ao analisar teoricamente as informações obtidas, percebemos que a assunto abordado é relativamente novo em meio a tantos estudos, e que inúmeros indivíduos apresentam os sintomas mencionados, procurando tratar apenas de forma convencional, a parte do seu corpo doente, sem tratar relativamente a principal causa.

Com isso, e por meio deste estudo, observamos a necessidade de o trabalhador buscar uma qualidade de vida, como também as empresas criarem espaços, atividades e formas de incluir o trabalhador num espaço mais relaxante e tranquilo, sobre as mais diversas formas citadas nesse artigo. As empresas também são responsáveis pela diminuição das ocorrências de estresse que podem vir a causar as doenças psicossomáticas. E como consequência disso contar em sua empresa com trabalhadores mais confiantes, dispostos e motivados com o clima mais agradável no ambiente de trabalho.

\section{REFERÊNCIAS:}

AMENDOLA, Gilberto. CAMBRICOLI, Fabiana. Estresse no trabalho vira doença, afirma OMS. Estadão São Paulo, 2019. Disponível em:https://noticias.uol.com.br/ultimasnoticias/agencia-estado/2019/05/28/estresse-no-trabalho-vira-doenca-

afirmaoms.htm?cmpid=copiaecola: Acesso em 25 de janeiro de 2020.

BOM SUCESSO, Edina de Paula. Trabalho e qualidade de vida. 1.ed. Rio de Janeiro: Dunya, 1997.

BRANCO, Luísa Vicente. Psicanálise e psicossomática: uma revisão. Revista Portuguesa de Psicossomática. 2005, 7 (1-2), 257-267. Disponível em: $<$ https://www.redalyc.org/articulo.oa?id=28770220 $>$ Acesso em 13 de fevereiro de 2020 .

CARLOTTO, Mary Sandra; PALAZZO, Lílian dos Santos. Síndrome de burnout e fatores associados: um estudo epidemiológico com professores. Cad. Saúde Pública [online]. 2006, vol. 22, n. 5, pp. 1017-1026. Disponível em: http://www.scielo.br/scielo.php?script=sci arttext\&pid=S0102311X2006000500014\&lng=pt\&nrm=iso Acesso em: 13 de fevereiro de 2020.

CARVALHO, Maiara Lene de. Qualidade de vida no trabalho versus condições psicossomáticas advindas do mercado de trabalho. REGRAD, UNIVEM/Marília-SP, v. 9, n. 1, p 67-84, agosto de 2016.

CUNHA, Maria Alice Gomes; LIMA, India Uyara Povoas Ferreira de; ALVES, Marcus Tadeu Bastos. $O$ ambiente de trabalho e as doenças psicossomáticas que influenciam na atividade laboral. SBDG - Sociedade Brasileira de Dinâmica dos grupos - Caderno 155 / Outubro /2016 
FERNANDES, Sandra Michelle Bessa de Andrade; MEDEIROS, Soraya Maria de; RIBEIRO, Laiane Medeiros. Estresse ocupacional e o mundo do trabalho atual: repercussões na vida cotidiana das enfermeiras. Revista Eletrônica de Enfermagem, v. 10, n. 2, p. 414-427, 2008. Disponível em: http://www.fen.ufg.br/revista/v10/n2/v10n2a13.htm Acesso em: 9 jan. 2013.

FERRARI, Antônio Eugênio Motta. Como combater o estresse. Hospital Vila da Serra, Junho/ 2012. Disponível em: https://www.hospitalviladaserra.com.br/como-combater-o-estresse/ Acesso em: 15 de março de 2020

GAZZOTTI, A. A., \& VASQUES-MENEZES, I. Suporte afetivo e o sofrimento psíquico em burnout. In CODO, W. (Org.) Educação: Carinho e trabalho. Rio de Janeiro: Vozes, 1999.

HAANEL, Charles F. Psicologia nova/Anthony R. Michalski; Charles F. Haanel; tradução Patrícia Fischer. $1^{a}$ Ed. São Paulo: Centro de estudos Vida \& Consciência, 2009.

JORGE, Iranise Moro Pereira. Doenças psicossomáticas relacionadas ao trabalho: estudo de caso. Dissertação (Pós-Graduação em Engenharia de Produção). UFSC - Universidade Federal de Santa Catarina, Florianópolis-SC, 2004.

LOPES, Rosimeri Bruno. Psicossomática e a Psicanálise. Psicologado, [S.1.]. (2012). Disponível em https://psicologado.com.br/psicossomatica/psicossomatica-e-a-psicanalise . Acesso em: 5 Mai 2020.

MELLO FILHO, Júlio. Concepção psicossomática: visão atual. São Paulo: Casa do Psicólogo, 2005.

RANGEL, Fabiana Bittencourtt; GODOI, Christiane Kleinübing. Sintomas Psicossomáticos e a Organização do Trabalho: um estudo em uma IE, RBGN- Revista Brasileira de Gestão em Negócios. São Paulo, v. 11, n. 33, p. 404-422, out/dez 2009.

RIBEIRO, Patrícia Oliveira. A influência da subjetividade e a emocionalidade no processo do adoecimento psicossomático. Monografia (Curso Psicologia). UniCEUB- Centro Universitário de Brasília, Brasília/DF, Junho de 2004. Disponível em: https://repositorio.uniceub.br/jspui/bitstream/123456789/2904/2/9960207.pdf Acesso em: 22 de Janeiro de 2020.

SEAWARD, B. L. Stress: aprenda a lidar com as tensões do dia-a-dia e melhore sua qualidade de vida. 6. ${ }^{\mathrm{a}}$ ed. São Paulo: Novo Conceito, 2009.

SÉPE, Ana Carla Horst. Estresse x Trabalho: Qualidade de vida nas organizações. Monografia (Curso de Especialização em RH - Gestão de Pessoas e Competências), Centro Universitário Filadélfia-UNIFIL, Londrina, 2011. Disponível em: < https://web.unifil.br/pergamum/vinculos/000006/00000697.pdf > Acesso em: 20 de dezembro de 2019.

SILVA, Ana Beatriz Barbosa. Mentes depressivas: as três dimensões da doença do século/ Ana Beatriz Barbosa Silva. 1. ${ }^{a}$ Ed. São Paulo: Principium, 2016.

TÓFOLI, Luís Fernando; GONÇALVES, Daniel Almeida; FORTES, Sandra. Somatização e sintomas sem explicação médica. Versão resumida do livro (Gusso \& Lopes, Tratado de medicina de família e comunidade: princípios, formação e prática, 2 vols.). Porto Alegre: Artmed, 2012.2 Disponível em:http://www.medicinanet.com.br/conteudos/revisoes/5385/somatizacao_e_sintomas_sem_e xplicacao_medica.htm Acesso em: 23 de fevereiro de 2020.

VOLICH, Rubens Marcelo. Psicossomática: de Hipocrates à Psicanálise. São Paulo: Casa do Psicólogo, 2000. 
i Psicóloga, Mestre em Educação pela UNIOESTE/Francisco Beltrão, docente na UNISEP. Email: jakefieira@hotmail.com

ii Administradora, mestra em Engenharia da Produção pela UTFPR/Ponta Grossa, docente UNIOESTE/Francisco Beltrão. Email: sandramoreira77@gmail.com

iii Administradora, especialista em Gestão Estratégica de Pessoas pela UNISEP/Dois Vizinhos, Sicredi. Email: cleusabordin@gmail.com 